\title{
Stop diabetes
}

\begin{abstract}
Diabetes is a modern day pandemic and its prevalence is increasing both in urban and rural parts of India beyond our expectation. Really it's an alarming signal for government health agencies to take strict action to stop diabetes and its complications. In this regard holistic approach from the government is the need of the hour. Government of India started the National Diabetes Control Programme. To strengthen this program a new plan of action has be outlined to tackle this menace.
\end{abstract}

Keywords: diabetes, control, government, health education
Volume 2 Issue 3 - 2015

\section{Ramachandra K \\ Department of Endocrinology Consultant Diabetilogists, India}

Correspondence: Ramachandra K, Department of Endocrinology Consultant Diabetilogists, Srivasa Diabetic center, Behind Janatha Bazar,VV Road, Mandya - 57I40I, Karnataka, India, Tel 91 9448642360, Email drram389@gmail.com
Abbreviations: DM, diabetes mellitus; NGO, non-governmental organisiation; IFG, impaired fasting glucose; IGT, impaired glucose tolerance; RBS, random blood sugar; FBS, fasting blood sugar; PPBS post prandial blood sugar; HTN, hypertension; DPN, diabetic peripheral neuropathy; ECG, ecocardiogram; LFT, liver function test; RFT, renal function test; MODY, maturity-onset of diabetes of the young; GDM, gestational diabetes mellitus; $\mathrm{CM}$, central health minister; PM, prime minister; MP, member of parliament; MLA, members of legislative assembly; MCI, medical council of india; DC, deputy commissioners; SP, superintendent of police; DHO, district health officer

\section{Introduction}

At this juncture, it is the burning issue of our country and prevalence rate of this diabetes mellitus (DM) increasing both in urban and rural population beyond our expectation. India harbors more than 62 million diabetics and prevalence is increasing steadily making India a diabetic capital of world. ${ }^{1,2}$ Also the National Urban Survey conducted across the metropolitan cities of India reported that the prevalence in urban population is thrice more common than rural population. Bangalore alone has a prevalence of 12.4 per cent making it a diabetic capital of Karnataka. ${ }^{3,4}$ Government of India started a National Diabetes Control Program in 1987 on a pilot basis without much success. Again in 2008 a National Program for Prevention and Control of Diabetes, Cardiovascular Disease and Stroke was launched with a special focus on risk reduction, early diagnosis and appropriate management of diabetes for the prevention of diabetes. ${ }^{4,5}$ But it was not focused effort and it includes funds for prevention of cancer, cardiovascular diseases and stroke. This is alarming sign for doctors and governments to take some permanent and focused measures to stop diabetes and its complications. The authors describes the new plan of action for each states to tackle is problem.

\section{Discussion}

To stop the rising disease burden in India, appropriate interventions should be done. But the big questions is, Is it possible to Stop Diabetes? Who has to stop it? Is it the government, doctors, nurses, non-governmental Organisiation (NGO), health workers who are responsible?

\section{Stop diabetes}

It is really a challenging task and appropriate government interventions and combined efforts from all the stakeholders of the society are required to reduce the disease burden in India.

\section{Team work}

Everyone should realize their responsibility and work to reach the goal. Following sections will describe the role of each stake holders in community.

\section{Role of doctors}

Doctors from government sectors, medical colleges, private practitioners and family physicians can facilitate the implementation of screening and early detection programmes, diabetes prevention, self-management counseling and therapeutic management of diabetes in accordance with the appropriate local guidelines and can form a backbone in controlling the diabetes epidemic. ${ }^{6}$

\section{Doctors in government hospitals}

They accounts for major share in this program. Both rural, taluk and district sectors has to play key role for screening and identify the pre diabetic conditions like impaired fasting glucose (IFG) and impaired glucose tolerance (IGT). Screening is very important to detect and identify pre diabetic condition and frank diabetic condition at the early stage to prevent complications. Early detection and proper diabetic awareness will defiantly post pone the diabetes and its complications. Most reliable glucometers are very important to get the proper result to rule out diabetic conditions.

Irregular values will create lot of confusions and may mislead the doctors and patients. During screening random blood sugar (RBS) positive patients (140-200mg) should be short listed for final diagnoses in all the nearby hospitals by giving proper date and maintance of diabetic diary to record all the values like fasting blood sugar (FBS), post prandial blood sugar (PPBS), hypertension (HTN) for future follow-up. This will help both the doctors and patients to know their status in every visit. In case of complication, they can refer the patients to nearby higher centers for further investigation. Eg: Diabetic retinopathy, diabetic peripheral neuropathy (DPN), ecocardiogram, 
ECG etc.. Profiles like thyroid, lipid, liver function test (LFT), renal function test (RFT) and haemoglobin levels is mandatory for the all the patients to treat according to the existing problem.

\section{Doctors in medical colleges}

Medical colleges are very important to train up young doctors, nurses and paramedical staff to play key role in this venture. They must select doctors (both physians and surgeons) with special interest for training to acquire more knowledge in the concerned specialties to manage properly. There are many one year fellowships program across the country concerned with diabetic care and management. It is propitious to start a separate diabetology department and podiatric department in all the medical colleges. Only Diabetic patients should be referred to these departments to take utmost care. Maintenance of diabetic registry regarding Type 1DM, Type 2DM, Maturity-onset of diabetes of the young (MODY) and gestational diabetes mellitus (GDM) in invaluable. This will definitely help the concerned department to give proper data, presentation and report to the government for suitable action. Podiatric department should perform foot related problems and try to provide artificial limbs for the amputated persons.

\section{Role of corporate doctors}

Screening and creating awareness regarding diabetes is very important aspect for corporate Doctors. Maintenance of diabetic registry to know the prevalence rate and other problems to take proper and regular action to check this challenge of diabetes. Proper training and prompt knowledge regarding diabetes, play a vital role in this process. Try to give diabetic dairy to all the patients and maintain hospital dairy to know the entire history of the patients. This will help the patient to monitor his/her glycemic level, hypertension and other parameters for better management.

\section{Role of family physicians}

Family physician role is crucial and very important in prevention of diabetes. Every family physician should be trained and give basic knowledge regarding diabetic health education and management. One year certificate course (weekly once CME eight hours) for family physicians by experts to upgrade the knowledge and management of diabetes. We should not interrupt their routine practices and lively hood. By this proper management he can manage more than eighty to ninety percent of diabetes especially pre diabetic conditions like IFG, IGT, MODI and GDM.

\section{Government involvement}

Diabetes prevention program_requires both money and man power. Unless the government invests money and makes proper planning, it is very difficult to proceed for this pilot project. It is a long run project with dedicated team of all sectors peoples: This should be implemented in national and state level by proper way of forming the committees in long run, irrespective of the centre and state government. This pilot project should continue for minimum of 10-15 years. At each level (Figure 1) appropriate monitoring committee is a crucial.

\section{National Level}

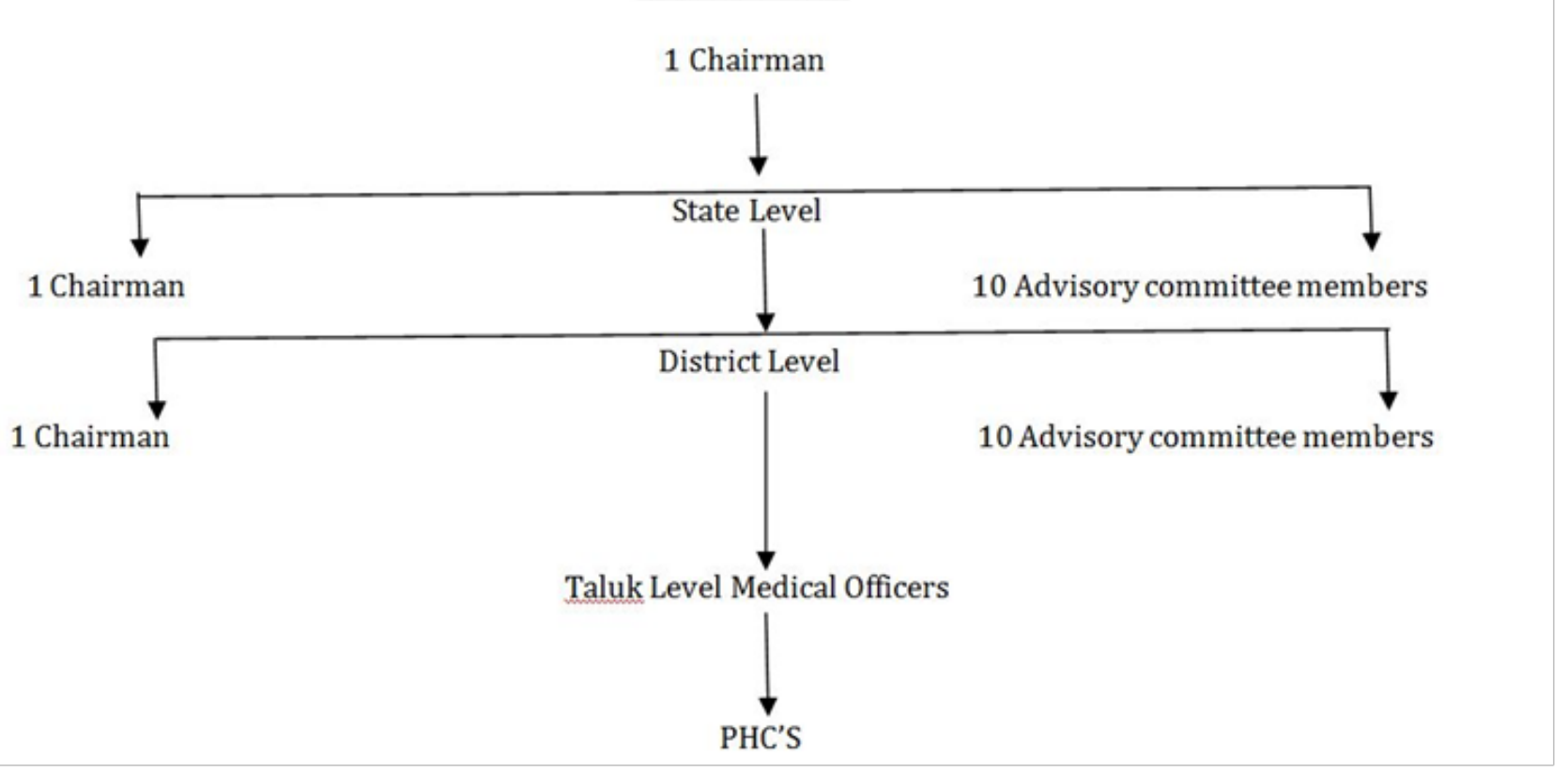

Figure I Organisation structure of diabetic prevention program.

\section{National level}

A committee at national level comprising of the following members could be important aspects in planning.

Silent features national committee for diabetic prevention

a. Central Chairman plus all state Chairman. b. Entire funding from the centre and monitoring with coordination of state level officers and ministers.

c. No state politician should interfere for this work, especially appointment and related works.

d. This committee should be independent and report to only state $\mathrm{CM}$, central health minister and prime minister. 
e. Member of Parliament (MP), Members of Legislative Assembly (MLA) and district ministers can attend the meeting and give their valuable suggestion. At any cost, they should not interfere for the function of this committee.

f. All state level and District level officers should coordinate and follow the instruction of the concerned committee.

g. National committee chairman should be equivalent to central cabinet minister.

h. All basic requirements should be provided by central and state government.

i. Monitoring every 3-6 months by central health minister and secretary to know the progress, development and lapses etc.

j. Involvement of experienced persons and organization service in this field can be utilized. Medical council of India (MCI) should play important role to implement this project in all the medical colleges.

\section{State level}

Similar to national level a state committee should be functional in implementing national decision.

\section{Silent features state committee for diabetic preven- tion:}

a. State level chairman ( equivalent to state cabinet rank minister )

b. District chairman in all the districts

c. State level chairman should form 10 members expert committee who are really interested in this noble venture and experienced in the field of diabetes.

d. State capital should be the head quarters (HQ). Committee should meet every three months to monitor all the district programs by inviting all the dist level chairmen for their progress and implementing the project ideas.

e. Medical education minister can be invited to take their suggestions once in 6 months to 12 months. All the progressive reports should be submitted to CM, medical education minister and health minister to know the real progress and implemented work.

f. Committee should print small brochures, related books and diabetic dairy and distribute to all the primary health centers (PHC), taluka hospitals, district hospitals and medical colleges to create awareness. Instruction should be given to all the concerned centers to distribute diabetic diary to all the diabetic patients to know the status and all parameters for patient and compulsory data to know the center (computerized).

g. Diabetic department should be started in all the colleges and district hospitals should have trained doctors. Taluk level medical officers should be given basic training for the management.

h. HQ should be provided basic amenities like separate building, office, staff and essential requirements.

i. Chairmen and 10 member committee should appoint the required staff in all the districts. This staffs are exclusively for diabetic project. At any case their service should not be diverted to some other project or work. j. Nurses and diabetes health educators should be trained and given proper materials to access the knowledge. Six months to one year compulsory training to create awareness, doing blood examination, blood pressure (BP) recording, DPN assessment and prevent foot related problems.

k. Training for doctors, nurses and health educators should be in their regional language to create awareness to the patients and community. All the brochures should be in local language. $\mathrm{Pu}-$ blishing book for doctors, nurses in a simple language for their concerned courses trainings.

1. HQ chairman and 10 member committee should work independently and their remunerations should be fixed by central government. Instruction should be given to all the district level officers like deputy commissioners (DC), superintendent of police (SP), district health officer (DHO) and director of medical collage to coordinate and treat the chairmen by protocal as cabinet rank power.

\section{Silent features district committee for diabetic preven- tion:}

District level chairmen should be DC and vice chairmen, director of medical education. Secretary should be Diabetolgist (HOD of medical college ) committee should be as fallows;

i. $\mathrm{DC}$

ii. SP

iii. Director of medical college \& preventive and social medicine staff.

iv. HOD of diabetology Department

v. Taluk level medical officers

vi. NGO'S (2 members)

vii. IMA president

This committee should monitor taluk level hospitals and PHC'S regarding diabetes prevention program. Health education maintenance of diabetic diary, maintenance of insulin, oral hypoglycemic agents (OHA), brochures and other related things in this project. This staffs services should be reserved exclusively for this program only. All the diabetes staffs should be monitored and asses the progress once in three months by the above committee.

\section{Functions of diabetic prevention program}

a. Adequate staffs and basic infrastructure for HQ (Head Quarters).

b. Chairmen and 10 members.

c. All district level program start at PHC level.

d. Pre diabetic detection and advice.

e. To establish mobile unit which should visit all the slum areas to identify the pre diabetic condition (IFG and IGT), frank DM should be sent nearby hospitals for further treatment and evaluation.

f. Early detection of end organ damages like diabetic retinopathy, cardiac problems, nephropathy and foot related problems. This is very crucial to lessen the burden on the government as well as patient family. 
g. All the district head quarters and medical colleges should be equipped with the entire podiatrist requirement, this staff and specialized Doctors. This team should consist of (1) opthomologist (2) cardiologist (3) Nephrologists (4) Diabetolgist (5) podiatrist their service should not be diverted other than this project.

h. Amputation prevention program is very much need of the hour and implemented in all the medical colleges. Special trained podiatric surgeon service is very important.

i. Keep separate Ophthalmology, echo, ECG, treadmill and angiogram for diabetic unit.

j. Trained Nurses should be appointed to access the DPN and foot related problems.

k. Keep separate staff for Diet management advice (well trained Msc nutrition) in all HQ Hospitals and medical colleges.

1. Free insulin should be given for all type I DM and poor DM2 patients misuse of insulin monitoring is prime important in all the centers. Perfect maintenance of OHA and insulin are very important and it should be available Dist committee and their use full suggestion should be implemented. Strict maintenance of diabetic records, dairy, medicine stock should be checked every month throughout misuse should be prevented at all the levels.

\section{Role of nurses}

Nurses should be given training in local language to create awareness to the patient and his relatives. Assessment of DPN, foot ulcers and management of diabetes. Well trained nurses in diabetes should be appointed in all the medical colleges, district hospitals and taluka level Hospitals. Their service should not be diverted for any other than prescribed duty.

\section{Role of NGO'S}

NGO 'S plays a vital role in diabetes prevention program for the community. Interested NGO'S should be trained to create awareness. They should arrange diabetic health education program in all the taluk and districts to create awareness to prevent diabetes. Distribution of small brochures to know what is diabetes? diet?, foot management and prevention of complications.

\section{Role of health workers}

Diabetes Health worker should be well trained in local language to give proper diabetes awareness and prevent complications.
They should organize small groups of diabetic patients to interact themselves to exchange their experience regarding diabetic control, diet and their problems in all the PHC centers. They should assess all the important out come and bring to the notice of the concerned officers to improve the quality life.

\section{Role of community/public}

Community should encourage this program and co-operate for the entire diabetes prevention program at all the levels. They should organize the people for all related program in all the centers. It should be voluntary service.

\section{Conclusion}

In long run with this properly planned program we may be able to prevent the diabetes and post pone the complications. Complete dedication of all concerned persons, no intervention of politicians' and political parties definitely, yield good progress with in the span of 5-15 years.

\section{Acknowledgements}

None.

\section{Conflicts of interest}

The author declares there is no conflict of interest.

\section{References}

1. Joshi SR, Parikh RM. India diabetes capital of the world now heading towards hypertension. J Assoc Physicians India. 2007;55:323-324.

2. Kumar A, Goel MK, Jain RB, et al. India towards diabetes control: Key issues. Australas Med J. 2013;6(10):524-531.

3. Ramachandran A, Snehalatha C, Kapur A, et al. Diabetes Epidemiology Study Group in India (DESI) High prevalence of diabetes and impaired glucose tolerance in India: National Urban Diabetes Survey. Diabetologia. 2001;44(9):1094-1101.

4. Zargar AH, Khan AK, Masoodi SR, et al. Prevalence of type 2 diabetes mellitus and impaired glucose tolerance in the Kashmir Valley of the Indian subcontinent. Diabetes Res Clin Pract. 2010;47(2):135-146.

5. Ministry of Health \& Family welfare. National Programme for Prevention and Control of Cancer, Diabetes, Cardiovascular Diseases \& Stroke (NPCDCS). New Delhi: Government of India. 2010.

6. Kaveeshwar SA, Cornwall J. The current state of diabetes mellitus in India. AMJ. 2014;7(1):45-48. 